http://jmscr.igmpublication.org/home/ ISSN (e)-2347-176x ISSN (p) 2455-0450 crossref DOI: https://dx.doi.org/10.18535/jmscr/v8i5.09

Journal Of Medical Science And Clinical Research

\title{
Neonatal Diabetes Mellitus (NDM): A Rare Case Report
}

\author{
Authors \\ Dr Sunil kumar Agarwalla ${ }^{1}$, Dr Gobinda Prasad Pradhan ${ }^{2}$ \\ ${ }^{1}$ Associate Professor, Dept. of paediatrics, MKCG MCH, Berhampur \\ ${ }^{2}$ Junior Resident $2^{\text {nd }}$ year, MKCG MCH, Berhampur
}

\begin{abstract}
Introduction: Diabetes mellitus (DM) is a common, metabolic disease characterised by hyperglycaemia as a cardinal biochemical feature. Diabetes mellitus most commonly occurs after the neonatal period and results from complex interactions between both environmental and incompletely penetrant genetic factors. Advances in molecular genetics over the past decade hastened the realization that diabetes that occurs very early life is most often due to underlying monogenic defects - disorders caused by mutation(s) in a single gene. Neonatal (or congenital) diabetes mellitus (NDM) is now known to occur in approximately 1 in 90,000-160,000 live births. There are over 20 known genetic causes for neonatal diabetes mellitus (NDM).

Case Report: We report a 45 days Mch presented to ER with history of increased feeding, increased urination for last 25 days, fever for 3 days, fast breathing \& decreased feeding for last 1 day. Patient is $3 r d$ order child born out of non-consanguineous marriage with uneventful perinatal history. Both Elder siblings doing well. Father died few months back in a road traffic accident, was suffering from type 2 DM \& was on OHA. Patient presented to ER with features of diabetic ketoacidosis (DKA). Management for DKA started as per the institution protocol. After complete workup the child was found to have permanent neonatal diabetes (NDM) \& discharged with subcutaneous Insulin. Prognosis \& course of the disease explained with advise for regular follow up.

Conclusion: Neonatal diabetes mellitus (also termed congenital diabetes, or diabetes of infancy) is likely to be due to an underlying monogenic defect. Usually it occurs under 6 months of age. Early recognition and urgent genetic testing are important for predicting the clinical course. Additionally early treatment of sulfonylurea-responsive types of neonatal diabetes may lead to better neurological outcomes. It is important to distinguish neonatal diabetes mellitus (NDM) from other causes of hyperglycaemia in the newborn. Other causes include infection, stress, inadequate pancreatic insulin production in the preterm infant. Insulin-dependent hyperglycaemia that persists longer than a week should raise suspicion for neonatal diabetes mellitus (NDM) and thus pointing towards genetic testing.

Keywords: Metabolic, genetic, mutations, neonatal diabetes, perinatal, sulfonylurea.
\end{abstract}

\section{Introduction}

Neonatal diabetes (NDM) is defined as hyperglycaemia occurring within the first few months of life lasting more than 2 weeks. It can be further classified into 1 . Transient neonatal diabetes, which remits early, or 2. Permanent neonatal diabetes, which requires lifelong Therapy. Approximately 50\% of Permanent DM in the newbornperiod is caused by mutations in the KCNJI1 (potassium inwardly rectifying 
channel J,member11) and $A B C C 8$ (adenosine triphosphate-binding cassette, subfamily $C$, member8) genes. These genes code for the Kir6.2 and SUR1 subunits of the adenosine triphosphatesensitive potassium channel, which is involved in an essential step in insulin secretion by the $\beta$-cell.

\section{Case Report}

We report a 45 days Mch presented to ER with history of increased feeding, increased urination for last 25 days, fever (Low grade, intermittent in nature, subsiding with medication) for 3 days, fast breathing \& decreased feeding for last 1 day. There was no history of previous similar episode, vomiting, loose motion, abdominal distension, cyanosis, crying during micturition, not gaining weight. Baby is 3rd order, term AGA (Birth weight $=3 \mathrm{~kg}$ ) born out of non-consanguineous marriage with uneventful perinatal history. Both Elder siblings doing well. Father died few months back in a road traffic accident, was suffering from type 2 DM \& was on OHA. Baby presented to ER with signs \& symptoms of severe respiratory distress, impaired mentation, acidotic breathing. On examination, the patient was tachypneic, febrile, lethargic, CVS/GI system examination being normal, Liver was enlarged $3 \mathrm{~cm}$ below the RCM (Liver span being $4.5-5 \mathrm{~cm}$, Normal), with no signs of raised ICT. On evaluating the patient, RBS showed High value, ABG showed $\mathrm{pH}=6.95$, $\mathrm{pCo}_{2}=10 \mathrm{mmHg}, \mathrm{K}^{+}=4.71 \mathrm{mmol} / \mathrm{L}, \mathrm{HCO}_{3}=5.2$ $\mathrm{mmol} / \mathrm{L}, \mathrm{AG}=32.6 \mathrm{mmol} / \mathrm{L}$, Urinalysis showed urine ketone body $3+$ to $4+/$ albumin $1+$ suggesting Severe DKA. Patient was managed with DKA protocol as per institution. CBC showed normocytic normochromic anaemia with neutrophilic leucocytosis, CRP +ve, HbA1c 9\%. Blood samples of the parents and patient's for genetic testing couldn't be done because of unavailability (Mutation analysis of KCNJ11, ABCC8 and INS genes). Patient was managed in ICU with IV Regular Insulin, $\mathrm{K}^{+}$, IV fluid. Patient's condition improved after 36 hrs of management with RBS came down below 200 $\mathrm{mg} / \mathrm{dL} \&$ later switched over to subcutaneous insulin. Insulin dose was titrated according to the feeding of patient \& discharged with Mixtard Insulin Pen. Prognosis \& course of the disease explained with advise for regular follow up. Now the patient is doing well, gaining weight.

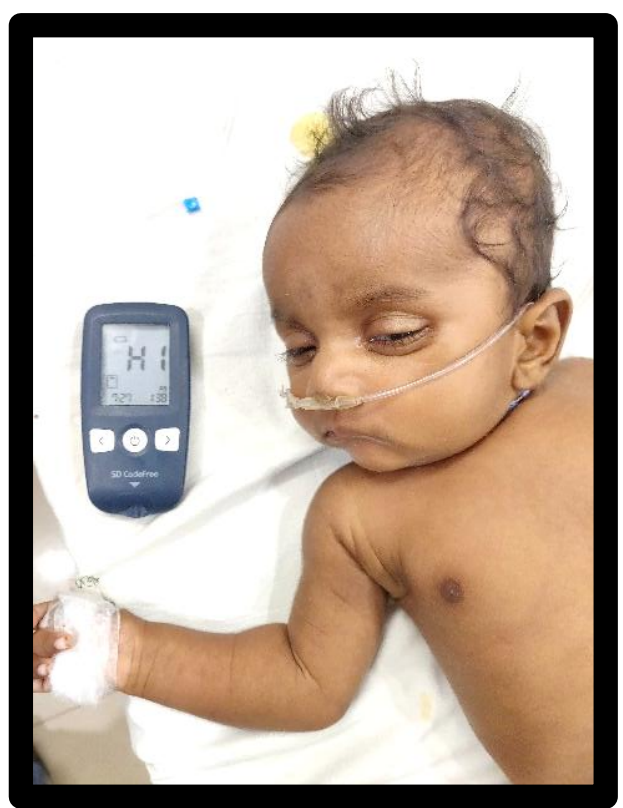

Fig. 1: Showing sunken eyes, lethargy, High RBS In an emergency room

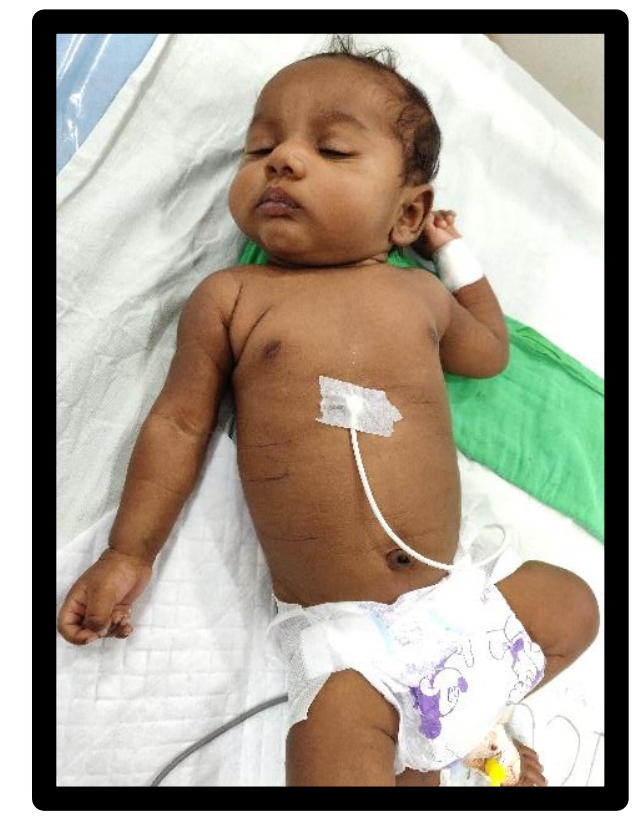

Fig. 2: Showing patient is in ICU with DKA management

\section{Discussion}

Monogenic diabetes is an extremely rare condition worldwide, representing $1-2 \%$ of all paediatric diabetes. This could be due to the very low index 
of suspicion, the rarity of the condition and the difficulty in accessing the tests needed to confirm it. Majority of infants with permanent neonatal diabetes (NDM) tend to have a low birth weight that is at the 3rd centile or lower and many presents with associated ketoacidosis.

Catch up growth is known to occur in these children once the insulin deficiency is corrected and most of them grow along the same growth centiles as other non-diabetic children with an overall good prognosis. The exceptions to this are a certain minority of children with a different type of mutation on the KCNJ11 gene. These patients may have associated neurological disease Characterized by developmental delay, muscle weakness, seizures and dysmorphic features.

\section{Conclusion}

As evidenced by the case report and the many emerging studies on the therapeutic and genetic screening, implications and early recognition of neonatal diabetes followed by appropriate therapy will lead to better patient outcomes. Advances in genetic screening technology with affordable cost will make more possible diagnosis and amicable outcome in the future.

Though hypoglycemia being a common biochemical entity in newborn but rarely hyperglycemia poses problem in the management. Its persistent nature will give a clue towards the possibility of permanent neonatal DM.

\section{References}

1. Von Muhlendahl KE, Herkenhoff $\mathrm{H}$. Long-term course of neonatal diabetes. $N$ Engl J Med. 1995;333(11):704 PubMed 8:10.1056/NEJM199509143331105

2. Hattersley A, Bruining J, Shield J, Njolstad P, Donaghue KC. The diagnosis and management of monogenic diabetes in children and adolescents. Pediatric diabetes. 2009;10 Suppl 12:3342:10.1111/j.1399-5448.2009.00571.x

3. Pearson ER, Flechtner I, Njolstad PR, Malecki MT, Flanagan SE, Larkin B, et al. Switching from insulin to oral sulfonylureas in patients with diabetes due to Kir6.2 mutations. New Engl J Med. 2006;355(5):467 PubMed-77:Doi 10.1056/Nejmoa061759

4. Al-Matary A, Hussain M, Nahari A, Ali J. Permanent neonatal diabetes mellitus. Am $J$ Case Rep. 2012;13:1435 PubMed :10.12659/AJCR.883242

5. Edghill EL, Flanagan SE, Patch AM, Boustred C,Parrish A, Shields B, et al. Insulin mutation screening in 1,044 patients with diabetes: mutations in the INS gene are a common cause of neonatal diabetes but a rare cause of diabetes diagnosed in childhood or adulthood. Diabetes. 2008;57(4):1034 PubMed 42:10.2337/db07-1405. 